\title{
Prevalence and characteristics of flavoured tobacco use among students in grades 10 through 12: a national cross-sectional study in Canada, 2012-2013
}

Yelena Bird ${ }^{1 *}$, Jennifer May², Chijioke Nwankwo ${ }^{1}$, Razi Mahmood ${ }^{1}$ and John Moraros ${ }^{1}$

\begin{abstract}
Background: Tobacco use is the leading cause of preventable death in Canada and the world. Despite documented decreases in the prevalence of smoking in Canada, increases in flavoured tobacco use by its youth poses a serious public health concern. This study examined the prevalence and characteristics of flavoured tobacco use among a national sample of Canadian students in grades 10 through 12.

Methods: This study used a cross-sectional design on a nationally generalizable, school-based, Youth Smoking Survey (YSS), 2012-2013. It incorporated data from a representative sample of 19,979 students in grades 10-12 from across Canada. Univariate and multivariate logistic regression models were used to examine differences in flavoured tobacco use (menthol cigarettes, flavoured little cigar or cigarillo, flavoured cigar, flavoured tobacco in water pipe [hookah]) by demographic (sex, grade and ethnicity) and social characteristics (friends, siblings, parents/guardians who are smokers and weekly personal spending money).

Results: This study found that $14.8 \%$ of the participating students used flavoured tobacco in the past 30-days. Results of the logistic regression analysis show that flavoured tobacco use was significantly higher among male students [(OR $=1.63 ; 95 \% \mathrm{Cl}=1.36-1.95)]$, who had at least one friend or sibling who smoke $[(\mathrm{OR}=2.20 ; \mathrm{Cl}=1.62$ to 2.99$)$ and $(\mathrm{OR}=$ $1.51 ; \mathrm{Cl}=1.22$ to 1.88$)$, respectively] and who received greater than $\$ 20 /$ week in personal spending money $[(\mathrm{OR}=1.76$; $\mathrm{Cl}=1.26$ to 2.45$)]$.

Conclusions: The results of our study indicate that flavoured tobacco use is a growing public health concern and has a strong appeal among youth in Canada. This is a particularly troubling finding, especially in light of the fact that there is a national ban on certain flavoured tobacco products. To be effective, strategies specifically tailored for youth using flavoured tobacco would require appropriate educational/prevention initiatives, more comprehensive legislation and better regulatory mechanisms.
\end{abstract}

Keywords: Flavoured tobacco, Adolescents, Canada

\footnotetext{
*Correspondence: yelena.bird@usask.ca

'School of Public Health, University of Saskatchewan, 104 Clinic Place, E-Wing

Health Sciences, Room 3322, Saskatoon, SK S7N 2Z4, Canada

Full list of author information is available at the end of the article
} 


\section{Background}

Tobacco use is the leading cause of preventable death in Canada and the world [1]. It has been associated with a range of medical conditions known to cause significant morbidity and mortality [1]. Current global estimates of the mortality from tobacco stand at 6 million deaths annually [2]. Since the 1990's, intense public health efforts have concentrated in reducing the burden of disease resulting from tobacco. These actions have effectively contributed to a steady decline of smoking rates over time $[3,4]$. In Canada, it is estimated that the prevalence of smoking is currently at its lowest point in nearly two decades [4] and the average number of cigarettes smoked daily has decreased by more than 2 cigarettes since 1999 [3].

These encouraging trends are threatened by the documented growing appeal of flavoured tobacco (menthol cigarettes, flavoured little cigar or cigarillo, flavoured cigar, flavoured tobacco in water pipe [hookah]) among youth $[5,6]$. It has been reported that approximately 2 of every 5 current youth smokers (approximately 126,000 young Canadians), use flavoured tobacco [7]. These tobacco products come in flavours that appeal to youth including vanilla, chocolate, bubblegum, watermelon, cherry, and strawberry. They are packaged in enticing colours aimed at youth and carry no health warnings. They are associated with less throat and upper respiratory tract irritation, which makes it easier to start and continue to smoke them and exposes youth to the long term effects of nicotine [8]. This puts youth at risk to become addicted and establish use patterns that persist into adulthood, making them life-long tobacco consumers [9].

Flavoured tobacco products have been falsely advertised as possible aids for smoking cessation and harm reduction by the tobacco industry [10]. Thus, it is not surprising to find that most young flavoured tobacco users believe them to be less harmful than regular cigarettes [11-13]. Similarly, one third of adults sampled in a US study believed the harmful effects of flavoured tobacco to be minimal [14]. These erroneous beliefs are fundamentally premised on an effective but misleading marketing campaign by the tobacco industry [15] and stand in stark contrast to the mounting evidence in the literature that details a number of deleterious effects attributed to the use of flavoured tobacco [16-18].

In Canada, concerns over the health effects of flavoured tobacco products $[5,19]$ along with their rise in popularity among youth [20] led the Canadian government to implement Bill C-32 in July 2010 [21]. Bill C-32 prohibits the sale of cigarettes, little cigars and cigarillos, and blunt wraps that weigh less than $1.4 \mathrm{~g}$ and contain flavouring agents (excluding menthol). However, Bill C32 does not cover all tobacco products and many manufacturers simply increased the weight of their products to more than $1.4 \mathrm{~g}$ to circumvent the law. Thus despite the national ban, it has been reported that more than half of high school students in Canada who smoke, use flavoured tobacco [6].

Flavoured tobacco use among Canadian youth is the result of a set of complex and dynamic interactions between youth and their social environment. However, the interactions between their demographic (sex, grade and ethnicity) and social characteristics (friends, siblings, parents/guardian who are smokers and weekly personal spending money) have not been sufficiently studied. The present study aims to use a large, nationally representative sample in order to identify the prevalence and characteristics associated with the use of flavoured tobacco among Canadian students in grades 10 through 12 .

\section{Methods}

\section{Study design}

This study used a cross-sectional, stratified design on a nationally generalizable, school-based Youth Smoking Survey (YSS) in 2012-2013. Stratification was based on the health region smoking rates (as determined by the Canadian Community Health Survey data), the participating school's postal code and the population size of major metropolitan areas [22]. The survey design and sample weights allow for population-based estimates and have been explained in detail elsewhere [23].

\section{Participants}

The 2012-2013 YSS involved a total of 38,667 student participants from grades 7-12 across 450 schools in Canada. Schools from the province of Manitoba and the Northwest, Nunavut and Yukon territories as well as students living in institutions or on First Nations reserves did not participate in the survey. Research has shown that students in lower grades (7-9) differ significantly from students in higher grades (10-12) with regard to their behaviours and a variety of measures relating to tobacco use [24]. Our study focused on students in grades $10-12(n=19,979)$.

\section{Variables explored \\ Outcome variable}

The outcome variable was current flavoured tobacco use (past 30-day use). The outcome variable was derived from a question in the YSS asking: "In the last 30-days, did you use any of the following flavoured tobacco products?" Responses included: "menthol cigarettes (Yes/No), flavoured little cigar or cigarillo (Yes/No), flavoured cigar (Yes/No), flavoured tobacco in water pipe (hookah) (Yes/No)." Students who answered yes to any of these four questions were classified as being current flavoured tobacco users. 


\section{Independent variables}

The independent variables of interest included the respondent's demographic (sex = male/female; ethnicity $=$ White, Black, Asian, Aboriginal, Hispanic; grade $=10$ 12) and social characteristics (how many of the respondent's friends, siblings and parents/guardians are smokers $=0,1,2,3$ or more; weekly personal spending money $=\$ 0$ to $>\$ 100)$.

\section{Data analysis}

The survey was weighted by the data provider in order to adjust for differential response rates across groups and to allow for generalization of the findings to the Canadian student population [22]. Our study used descriptive analysis to summarize the basic features of the data, looking at frequencies and distributions of the outcome and independent variables of interest. Univariate analysis was conducted to determine the crude association between each of the independent variables (sex, grade, ethnicity, number of friends, siblings, and parents/guardians who smoke and weekly personal spending money) and the outcome variable of interest (flavoured tobacco use). Logistic regression modelling was carried out using the PROC SURVEYLOGISTIC command to examine the relationship between flavoured tobacco use and the independent variables of interest.

Assumptions of logistic regression were checked, and backwards elimination strategy was used, when developing the models. When variables were removed, confounding was assessed at each stage. If there was a change in the effect estimate of the primary predictor by $20 \%$ or more with the inclusion of a variable, the variable would be retained in the model as a confounder. All possible two-way interactions involving the predictor variable and the variables of interest were assessed using a $p$-value of 0.05 for statistical significance. All analysis was carried out using SAS version 9.3.

\section{Results}

In $2012-2013,14.8 \%$ of the participating students from grades $10-12$, self-identified as having used flavoured tobacco over the past 30-days in Canada. Past 30-day use of flavoured tobacco as a percentage was highest among males $(18.8 \%)$, who attended $12^{\text {th }}$ grade $(17.4 \%)$, and who self-reported being Aboriginal (23.9\%), Hispanic (21.3\%) and Black (19.0\%). Also, youth who used flavoured tobacco products in the past 30-days, reported having one or more friends who smoked (68.3\%), one or more siblings who smoked (91.2\%), and one or more parents/guardians who smoked (63.9\%). In terms of their weekly personal spending, 23.3\% reported having greater than $\$ 100$ per week to spend on themselves, while $8.7 \%$ reported having no personal weekly monies (Table 1 ).
Univariate analysis suggests that sex $(p<0.0001)$, grade $(p<0.0003)$, ethnicity $(p<0.0001)$, friends who smoke $(p$ $<0.0001)$, siblings who smoke $(p<0.0001)$, parents/ guardians who smoke $(p<0.0001)$ and weekly personal spending money $(p<0.0001)$ were significantly associated with flavoured tobacco use among students in grades 10-12. Odds ratios are shown in relation to a reference category for each variable (Table 2).

Multivariate logistic regression analysis examined the odds of being a flavoured tobacco user. The results found that male students $(\mathrm{OR}=1.63,95 \% \mathrm{CI}$ : 1.36 to $1.95)$, who had at least one friend $(\mathrm{OR}=2.20,95 \% \mathrm{CI}$ : 1.62 to 2.99 ) or sibling ( $\mathrm{OR}=1.51, \mathrm{CI}: 1.22$ to 1.88 ) who smoke and who received greater than $\$ 20 /$ week in personal spending money $(\mathrm{OR}=1.76 ; \mathrm{CI}=1.26$ to 2.45$)$ were significantly associated with using flavoured tobacco when compared to students who did not (Table 3).

The variables of "friends who smoke" showed a graded association of a student using flavoured tobacco as the number of friends who smoke increased from one (OR $=2.20,95 \% \mathrm{CI}: 1.62$ to 2.99$)$ to two friends $(\mathrm{OR}=3.80$, 95\% CI: 2.71 to 5.31 ) and three or more friends who smoke (OR $=7.08,95 \% \mathrm{CI}: 5.66$ to 8.86$)$, when compared to students who reported having no friends who smoke. A similar pattern was seen with siblings who smoke, as individuals who had one sibling $(\mathrm{OR}=1.51,95 \% \mathrm{CI}: 1.22$ to 1.88$)$, two siblings $(1.55,95 \% \mathrm{CI}: 1.09$ to 2.20$)$ and three or more siblings who smoke $(\mathrm{OR}=3.40,95 \% \mathrm{CI}$ : 2.33 to 4.96 ) demonstrated a graded association with flavoured tobacco use, when compared to students with no siblings who smoke (see Table 3). There were no statistically significant associations with parent/guardian smokers or by high school grade (grade 10,11, 12) and a student using flavoured tobacco.

\section{Discussion}

This study sought to determine the prevalence and characteristics associated with the use of flavoured tobacco among a national sample of Canadian students in grades 10 through 12. It provides insight and adds knowledge to our understanding of flavoured tobacco use among youth in Canada along two discrete but interrelated perspectives (demographic and social).

From a demographic perspective, our study found that $14.8 \%$ of the students reported using flavoured tobacco. This is similar to the prevalence reported among high school students in the US [25] and previous studies in Canada $[6,26]$. Flavoured tobacco is becoming increasingly popular among students as evidenced by the fact that one out of every three Canadian youth has tried it [7] and sales have increased by eightfold in six years [21]. This may be a reflection of the widespread belief by youth that flavoured tobacco is a better alternative to 
Table 1 Descriptive characteristics of the study population among 10-12 grade school students in Canada, 2012-2013

\begin{tabular}{|c|c|c|c|c|}
\hline Variables & & $\begin{array}{l}\text { Flavoured Tobacco } \\
\text { Use (Past } 30 \text { days) }\end{array}$ & $\begin{array}{l}\text { No Flavoured Tobacco } \\
\text { Use (Past } 30 \text { days) }\end{array}$ & Total (N) \\
\hline \multicolumn{5}{|l|}{ Outcome Variable } \\
\hline \multicolumn{2}{|l|}{$\begin{array}{l}\text { Flavoured Tobacco Use } \\
\text { (Past } 30 \text { days) }\end{array}$} & $14.77 \%$ & $85.23 \%$ & 19979 \\
\hline \multicolumn{5}{|l|}{ Independent Variables } \\
\hline \multirow[t]{2}{*}{$\operatorname{Sex}(n=19979)$} & Male & $18.8 \%$ & $81.2 \%$ & 9808 \\
\hline & Female & $10.9 \%$ & $89.1 \%$ & 10171 \\
\hline \multirow[t]{3}{*}{ Grade } & Tenth & $12.7 \%$ & $87.3 \%$ & 7544 \\
\hline & Eleventh & $15.0 \%$ & $85.0 \%$ & 6982 \\
\hline & Twelfth & $17.4 \%$ & $82.6 \%$ & 5453 \\
\hline \multirow[t]{5}{*}{ Ethnicity ( $n=18818)$} & White & $14.5 \%$ & $85.5 \%$ & 14389 \\
\hline & Black & $19.0 \%$ & $81.0 \%$ & 814 \\
\hline & Asian & $7.5 \%$ & $92.5 \%$ & 1942 \\
\hline & Aboriginal & $23.9 \%$ & $76.1 \%$ & 1270 \\
\hline & Hispanic & $21.3 \%$ & $78.7 \%$ & 403 \\
\hline \multirow{4}{*}{$\begin{array}{l}\text { Friend Smokers } \\
(n=18048)\end{array}$} & None & $4.6 \%$ & $95.5 \%$ & 9861 \\
\hline & One & $12.1 \%$ & $87.9 \%$ & 2278 \\
\hline & Two & $19.7 \%$ & $80.3 \%$ & 1571 \\
\hline & Three or more & $36.5 \%$ & $63.5 \%$ & 4338 \\
\hline \multirow{4}{*}{$\begin{array}{l}\text { Sibling Smokers } \\
(n=18141)\end{array}$} & None & $11.0 \%$ & $89.0 \%$ & 14149 \\
\hline & One & $23.2 \%$ & $76.8 \%$ & 2763 \\
\hline & Two & $25.9 \%$ & $74.1 \%$ & 718 \\
\hline & Three or more & $42.1 \%$ & $57.9 \%$ & 511 \\
\hline \multirow{4}{*}{$\begin{array}{l}\text { Parent/Guardian Smokers } \\
(n=18921)\end{array}$} & None & $10.4 \%$ & $89.6 \%$ & 10935 \\
\hline & One & $16.5 \%$ & $83.5 \%$ & 4284 \\
\hline & Two & $20.1 \%$ & $79.9 \%$ & 2107 \\
\hline & Three or more & $27.3 \%$ & $72.7 \%$ & 1595 \\
\hline \multirow{7}{*}{$\begin{array}{l}\text { Weekly Personal Spending } \\
\text { Money }(n=16546)\end{array}$} & $\$ 0$ & $8.7 \%$ & $91.3 \%$ & 2783 \\
\hline & $\$ 1-\$ 5$ & $12.5 \%$ & $87.5 \%$ & 869 \\
\hline & $\$ 6-\$ 10$ & $10.3 \%$ & $89.7 \%$ & 1199 \\
\hline & $\$ 11-\$ 20$ & $12.6 \%$ & $87.4 \%$ & 2594 \\
\hline & $\$ 21-\$ 40$ & $17.1 \%$ & $82.9 \%$ & 2639 \\
\hline & $\$ 40-\$ 100$ & $16.7 \%$ & $83.3 \%$ & 2733 \\
\hline & $>\$ 100$ & $23.3 \%$ & $76.7 \%$ & 3729 \\
\hline
\end{tabular}

regular tobacco, less harmful to their health and more fun to use $[15,27]$. Our findings also demonstrate a progressive rise in flavoured tobacco use with increasing grades $10-12$ among Canadian students (16-18 years old). This is a period of identity development, increased curiosity and risk taking behaviour [28]. The tobacco industry, exploits the inherent vulnerability of this transitional period by focusing their trendy marketing and advertising campaigns on themes that resonate with youth such as independence, sophistication, fun and rebellion [9].
In our study, male students were significantly more likely to use flavoured tobacco compared to females. This was consistent with evidence reported elsewhere in the literature [11-13]. It is possible that male students have higher risk taking proclivities/behaviours along with easier access and higher affordability levels to flavoured tobacco when compared to females. Students who selfidentified as Aboriginal or Hispanic had increased odds of using flavoured tobacco when compared to White students but these differences were not statistically significant. Our results are corroborated by several 
Table 2 Univariate analysis of flavoured tobacco use among 10-12 grade school students in Canada, 2012-2013

\begin{tabular}{|c|c|c|c|}
\hline Variables & & $\begin{array}{l}\text { Odds Ratio (95\% Cl: } \\
\text { Lower to Upper) }\end{array}$ & $\begin{array}{l}p \text {-value } \\
(a=0.05)\end{array}$ \\
\hline Sex (Ref = Female) & Males & 1.73 (1.48 to 2.02 ) & $<0.0001$ \\
\hline \multirow[t]{2}{*}{ Grade $($ Ref $=$ Grade 10) } & Grade 11 & 1.20 (1.00 to 1.44$)$ & \multirow[t]{2}{*}{0.0003} \\
\hline & Grade 12 & 1.53 (1.24 to 1.87$)$ & \\
\hline \multirow[t]{4}{*}{ Ethnicity (Ref = White) } & Black & 0.83 (0.58 to 1.19$)$ & \multirow[t]{4}{*}{$<0.0001$} \\
\hline & Asian & 0.53 (0.39 to 0.71$)$ & \\
\hline & Aboriginal & 2.17 (1.74 to 2.70$)$ & \\
\hline & Hispanic & 1.49 (1.03 to 2.17$)$ & \\
\hline \multirow{3}{*}{$\begin{array}{l}\text { Friend Smokers } \\
\text { (Ref = None) }\end{array}$} & 1 & 2.82 (2.05 to 3.88 ) & \multirow[t]{3}{*}{$<0.0001$} \\
\hline & 2 & 5.28 (3.82 to 7.30$)$ & \\
\hline & 3 or more & $10.47(8.56$ to 12.81$)$ & \\
\hline \multirow{3}{*}{$\begin{array}{l}\text { Sibling Smokers } \\
\text { (Ref = None) }\end{array}$} & 1 & 2.82 (2.29 to 3.48 ) & \multirow[t]{3}{*}{$<0.0001$} \\
\hline & 2 & 3.43 (2.59 to 4.54$)$ & \\
\hline & 3 or more & 7.07 (5.01 to 9.97 ) & \\
\hline \multirow{3}{*}{$\begin{array}{l}\text { Parent/Guardian Smokers } \\
\text { (Ref = None) }\end{array}$} & 1 & 1.76 (1.44 to 2.15$)$ & \multirow[t]{3}{*}{$<0.0001$} \\
\hline & 2 & 2.25 (1.82 to 2.79$)$ & \\
\hline & 3 or more & 3.63 (2.80 to 4.69$)$ & \\
\hline \multirow{6}{*}{$\begin{array}{l}\text { Weekly Personal Spending } \\
\text { Money (Ref = Zero) }\end{array}$} & $\$ 1-\$ 5$ & 1.05 (0.72 to 1.53$)$ & \multirow[t]{6}{*}{$<0.0001$} \\
\hline & $\$ 6-\$ 10$ & 1.16 (0.81 to 1.68$)$ & \\
\hline & $\$ 11-\$ 20$ & 1.73 (1.28 to 2.34$)$ & \\
\hline & $\$ 21-\$ 40$ & 2.33 (1.75 to 3.09 ) & \\
\hline & $\$ 41-\$ 100$ & 2.23 (1.65 to 3.00$)$ & \\
\hline & $>\$ 100$ & 3.76 (2.93 to 4.81$)$ & \\
\hline
\end{tabular}

Flavoured Tobacco Use $=1$ if: Menthol cigarette or Flavoured little cigar or cigarillo or Flavoured cigar or Flavoured tobacco in a water-pipe (hookah) was used in the past 30 days

Flavoured Tobacco Use $=0$ if: I did not use any of these things (above) in the past 30 days

Canadian studies that show an increased burden of smoking among Aboriginal youth [29, 30]. However, there is not much in the literature detailing the smoking situation of Hispanic youth in Canada. This is an area that requires further study as evidence from Mexico [31, $32]$ and the US $[9,11]$ shows that Hispanic youth are at an increased risk for smoking behaviours, including the use of flavoured tobacco [33].

From a social perspective, we found a significant association between the number of siblings or friends who smoke and the likelihood of a student using flavoured tobacco after adjusting for all other covariates. Interestingly, our study found peers to have a more pronounced influence on students' use of flavoured tobacco when compared to their siblings and even their parents/guardians. There are multiple mechanisms that may help explain this finding. It may be the result of the increased amount of time youth spend with their peers [34] and the opportunities for social learning [35], ease of access to flavoured tobacco [35-37] and direct pressures to
Table 3 Factors associated with flavoured tobacco use by logistic regression analyses among 10-12 grade school students in Canada, 2012-2013

\begin{tabular}{|c|c|c|c|}
\hline Variables & & $\begin{array}{l}\text { Odds Ratio (95\% Cl: } \\
\text { Lower to Upper) }\end{array}$ & $\begin{array}{l}p \text {-value } \\
(a=0.05)\end{array}$ \\
\hline Sex (Ref = Female $)$ & Males & 1.63 (1.36 to 1.95$)$ & $<0.0001$ \\
\hline \multirow[t]{4}{*}{ Ethnicity (Ref = White) } & Black & 0.94 (0.60 to 1.45$)$ & \multirow[t]{4}{*}{0.0470} \\
\hline & Asian & 0.65 (0.46 to 0.92$)$ & \\
\hline & Aboriginal & 1.19 (0.88 to 1.60$)$ & \\
\hline & Hispanic & 1.32 (0.84 to 2.08 ) & \\
\hline \multirow{3}{*}{$\begin{array}{l}\text { Friend Smokers } \\
\text { (Ref = None) }\end{array}$} & 1 & 2.20 (1.62 to 2.99$)$ & \multirow[t]{3}{*}{$<0.0001$} \\
\hline & 2 & $3.80(2.71$ to 5.31$)$ & \\
\hline & 3 or more & 7.08 (5.66 to 8.86 ) & \\
\hline \multirow{3}{*}{$\begin{array}{l}\text { Sibling Smokers } \\
\text { (Ref = None) }\end{array}$} & 1 & 1.51 (1.22 to 1.88$)$ & \multirow[t]{3}{*}{$<0.0001$} \\
\hline & 2 & 1.55 (1.09 to 2.20$)$ & \\
\hline & 3 or more & 3.40 (2.33 to 4.96$)$ & \\
\hline \multirow{6}{*}{$\begin{array}{l}\text { Weekly Personal Spending } \\
\text { Money (Ref = Zero) }\end{array}$} & $\$ 1-\$ 5$ & 1.05 (0.68 to 1.62$)$ & \multirow[t]{6}{*}{$<0.0001$} \\
\hline & $\$ 6-\$ 10$ & 1.12 (0.71 to 1.76$)$ & \\
\hline & $\$ 11-\$ 20$ & 1.23 (0.87 to 1.76$)$ & \\
\hline & $\$ 21-\$ 40$ & 1.76 (1.26 to 2.45$)$ & \\
\hline & $\$ 41-\$ 100$ & 1.62 (1.17 to 2.26$)$ & \\
\hline & $>\$ 100$ & 2.46 (1.82 to 3.33$)$ & \\
\hline
\end{tabular}

Flavoured Tobacco Use $=1$ if: Menthol cigarette or Flavoured little cigar or cigarillo or Flavoured cigar or Flavoured tobacco in a water-pipe (hookah) was used over the past 30 days

Flavoured Tobacco Use $=0$ if: I did not use any of these things (above) in the last 30 days

identify, bond and gain their respect and acceptance at this critical time of their development [38].

Finally, we found that the more money a student had available to spend in a week, the higher the likelihood of them using flavoured tobacco. Several studies have associated youth's access to spending money with their risk of smoking [6, 39, 40]. A study in Ontario, Canada, found that even small differences in weekly spending allowance had an incremental and significant impact on the smoking status among youth. It reported that students who had less than $\$ 10$ per week were significantly less likely to be smokers, those with $\$ 20$ per week were significantly more likely to be experimental smokers, and students with more than $\$ 30$ per week were significantly more likely to be current smokers [40].

\section{Strengths and limitations}

Flavoured tobacco use as defined for the purposes of this study represented use in the past 30-days. This time limitation may not allow us to adequately determine the volume or frequency of use. Secondly, there were no objective measures of flavoured tobacco use since all the measures in the study were self-reports. Third, the YSS is a school-based survey and therefore, youth who do not attend school were excluded from our sample. 
Lastly, the study used of a cross-sectional design and therefore, it is unable to draw causal inferences between the variables studied and flavoured tobacco use. Despite the aforementioned limitations, this study also has a number of significant strengths. It used a national sample that was large in size and representative in scope and specifically looked to identify the prevalence and demographic and social characteristics in the use of flavoured tobacco among Canadian students in grades 10-12.

\section{Conclusions}

The results of our study show that flavoured tobacco use is a growing public health concern and has a strong appeal among youth in Canada. This is a particularly troubling finding, especially in light of the fact that there is a national ban on certain flavoured tobacco products. To be effective, strategies specifically tailored for youth using flavoured tobacco would require appropriate educational/prevention initiatives, more comprehensive legislation and better regulatory mechanisms. These interventions are urgently needed in order to prevent erosion and safeguard the significant gains made in our efforts to reduce smoking rates in Canada.

\section{Abbreviations}

US: United States; YSS: Youth smoking survey

\begin{abstract}
Acknowledgments
The Youth Smoking Survey is a product of the pan-Canadian capacity building project funded through a contract between Health Canada and the Propel Centre for Population Health Impact from 2008 through 2011. The YSS consortium includes Canadian tobacco control researchers from all provinces and provided training opportunities for university students at all levels. The views expressed herein do not necessarily represent the views of Health Canada. We gratefully acknowledge The Propel Centre for Population Health Impact for kindly granting us access to the micro-files of the Health Data Repository.
\end{abstract}

\section{Funding}

This research was supported in part by a matching collaborative grant from the Lung Association of Saskatchewan and the School of Public of Public Health, University of Saskatchewan.

\section{Availability of data and materials}

All data and materials are stored in the Health Data Repository, The Propel Centre for Population Health Impact, University of Waterloo, Ontario, Canada.

\section{Authors' contributions}

$\mathrm{YB}, \mathrm{JM}$ and $\mathrm{JM}$ s were involved in the study conception and design. RM, CN and JMs were responsible for the data analysis. All authors contributed to the discussion, interpreted the findings, helped write, reviewed/edited the manuscript for intellectual content, and read and approved the final manuscript.

\section{Competing interests}

The authors declare that they have no competing interests.

\section{Consent for publication}

Not applicable.

\section{Ethics approval and consent to participate}

The Youth Smoking Survey (YSS) was implemented with the cooperation support and funding of Health Canada, and conducted by a consortium of researchers across Canada and coordinated centrally by the Propel Centre for Population Health Impact, University of Waterloo. It was approved by the
Health Canada Research Ethics Board, and appropriate school board and public health ethics committees. Responding to this survey was voluntary.

\section{Publisher's Note}

Springer Nature remains neutral with regard to jurisdictional claims in published maps and institutional affiliations.

\section{Author details}

${ }^{1}$ School of Public Health, University of Saskatchewan, 104 Clinic Place, E-Wing Health Sciences, Room 3322, Saskatoon, SK S7N 2Z4, Canada. ${ }^{2}$ Health

Promotion, Lung Association of Saskatchewan, Saskatoon, Canada.

Received: 6 November 2016 Accepted: 20 March 2017

Published online: 24 March 2017

\section{References}

1. World Health Organization. Tobacco, Fact Sheet. 2016. http://www.who.int/ mediacentre/factsheets/fs339/en/. Accessed 9 July 2016.

2. Shields M. The Journey to Quitting Smoking. Statistics Canada Health Reports. 2005;16(3). Statistics Canada Catalogue no. 82-003. http://www.statcan.gc.ca/ studies-etudes/82-003/archive/2005/7839-eng.pdf. Accessed 9 July 2016.

3. Reid JL, Hammond D, Rynard VL, et al. Tobacco Use in Canada: Patterns and Trends, 2014 edition. Waterloo, ON: Propel Centre for Population Health Impact, University of Waterloo. http://www.tobaccoreport.ca/2014/. Accessed 9 July 2016

4. Statistics Canada. Health fact sheets, smoking. 2014. http://www.statcan.gc. ca/pub/82-625-x/2015001/article/14190-eng.htm\#n1. Accessed 9 July 2016.

5. Minaker LM, Alanna S, Nghia N, Sunday A, Manske SR. Cigarette smoking susceptibility among youth alternate tobacco product users: implications of flavoured tobacco from a national cross-sectional Canadian sample (YSS 2012/2013). BMJ Open. 2015:5:e009549.

6. Minaker LM, Ahmed R, Hammond D, Manske SR. Flavored tobacco use among Canadian students in grades 9 through 12: prevalence and patterns from the 2010-2011 youth smoking survey. Prev Chronic Dis. 2014;11:E102.

7. Health Canada. Summary of results of the youth smoking survey 2012-2013. 2014. https://www.canada.ca/en/health-canada/services/publications/ healthy-living/summary-results-youth-smoking-survey-2012-2013.html. Accessed 1 Mar 2017.

8. World Health Organization. The scientific basis for tobacco product regulation: report of a WHO study group. 2007. Available from: http://www.who.int/ tobacco/global_interaction/tobreg/9789241209458.pdf. Accessed 17 Jan 2017.

9. US Department of Health and Human Services. Preventing tobacco use among youth and young adults: a report of the Surgeon General. Atlanta, GA, CDC; 2012. https://www.surgeongeneral.gov/library/reports/preventingyouth-tobacco-use/. Accessed 14 Feb 2017.

10. Richardson A, Ganz O, Vallone D. Tobacco on the web: surveillance and characterisation of online tobacco and e-cigarette advertising. Tob Control. 2014:24(4):341-7.

11. King BA, Tynan MA, Dube SR, Arrazola R. Flavored-little-cigar and flavoredcigarette use among U.S. middle and high school students. J Adolesc Health. 2014;54(1):40-610.

12. Leatherdale ST, Rios P, Elton-Marshall T, Burkhalter R. Cigar, cigarillo, and little cigar use among Canadian youth: are we underestimating the magnitude of this problem? J Prim Prev. 2011;32(3-4):161-7010.

13. Delnevo C, Giovenco D, Ambrose B, Corey C, Conway K. Preference for flavoured cigar brands among youth, young adults and adults in the USA. Tob Control. 2014:24(4):389-94

14. King B, Dube S, Tynan M. Flavoured cigar smoking among U.S. Adults: findings from the 2009-2010 National Adult Tobacco Survey. Nicotine Tob Res. 2012;15(2):608-14

15. Lewis MJ, Wackowski O. Dealing with an innovative industry: a look at flavored cigarettes promoted by mainstream brands. Am J Public Health. 2006;96(21):244-51.

16. Hoffman AC. The health effects of menthol cigarettes as compared to non-menthol cigarettes. Tob Induc Dis. 2011;9 Suppl 1:S7.

17. Villanti A, Richardson A, Vallone D, Rath J. Flavored tobacco product use among U.S. young adults. Am J Prev Med. 2013;44(4):388-91.

18. El-Zaatari Z, Chami H, Zaatari $G$. Health effects associated with waterpipe smoking. Tob Control. 2015;24 Suppl 1:131-43. 
19. Health Canada. Canadian Tobacco Use Monitoring Survey 2009-2010. http://www.hc-sc.gc.ca/hc-ps/tobac-tabac/research-recherche/stat/_ctumsesutc_2011/ann_summary-sommaire-eng.php. Accessed 17 Feb 2017.

20. Mutti S, Hammond D, Borland R, Cummings MK, O'Connor RJ, Fong GT. Beyond light and mild: cigarette brand descriptors and perceptions of risk in the International Tobacco Control (ITC) four country survey. Addiction. 2011;106(6):1166-7510.

21. Bill C-32. An Act to Amend the Tobacco Act, 2009. Health Canada 2009. http://www.hc-sc.gc.ca/hc-ps/tobac-tabac/legislation/federal/2009_factrenseignements-eng.php. Accessed 1 Mar 2017.

22. Burkhalter R, Cumming T, Rynard V, Manske S. 2012/2013 Youth Smoking Survey microdata user guide. Waterloo (ON): Propel Centre for Population Health Impact, University of Waterloo, 2013:1-47. https://uwaterloo.ca/ canadian-student-tobacco-alcohol-drugs-survey/sites/ca.canadian-studenttobacco-alcohol-drugs-survey/files/uploads/files/yss12_user_guide_en_v5_ 20131231.pdf. Accessed 1 Mar 2017.

23. Leos-Toro C, Hammond D, Manske S. A cross-sectional examination of medicinal substance abuse and use of nonmedicinal substances among Canadian youth: findings from the 2012-2013 youth smoking survey. CMAJ Open. 2015;3(4):E387-94.

24. Health Canada. Summary of results of the Youth Smoking Survey 20102011. 2014. http://www.hc-sc.gc.ca/hc-ps/tobac-tabac/research-recherche/ stat/_survey-sondage_2010-2011/result-eng.php. Accessed 1 Mar 2017.

25. Neff L, Arrazola R, Caraballo R, Corey C, Cox S, King B, et al. Frequency of tobacco use among middle and high school students - United States, 2014. MMWR Morb Mortal Wkly Rep. 2015;64(38):1061-5.

26. Freedman KS, Nelson NM, Feldman LL. Smoking initiation among young adults in the United States and Canada, 1998-2010: a systematic review. Prev Chronic Dis. 2012;9(1):E05.

27. Feirman S, Lock D, Cohen J, Holtgrave D, Li T. Flavoured tobacco products in the United States: a systematic review assessing use and attitudes. Nicotine Tob Res. 2015;18(5):739-49.

28. Albert D, Steinberg L. Judgment and decision making in adolescence. J Res Adolesc. 2011;21(1):211-24

29. Elton-Marshall T, Leatherdale S, Burkhalter R. Tobacco, alcohol and illicit drug use among aboriginal youth living off-reserve: results from the youth smoking survey. Can Med Assoc J. 2011:183(8):E480-6.

30. Retnakaran R, Hanley A, Connell P, Harris S, Zinman B. Cigarette smoking and cardiovascular risk factors among aboriginal Canadian youths. Can Med Assoc J. 2005;173(8):885-9.

31. Bird Y, Moraros J, Olsen LK, Forster-Cox S, Staines-Orozco H, Buckingham RW. Smoking practices, risk perception of smoking, and environmental tobacco smoke exposure among 6th-grade students in Ciudad Juárez, Mexico. Nicotine Tob Res. 2007:9(2):195-203.

32. Bird Y, Staines-Orozco H, Moraros J. Adolescents' smoking experiences, family structure, parental smoking and socio-economic status in Ciudad Juárez, Mexico. Int J Equity Health. 2016;15(1):29.

33. Rath J, Villanti A, Williams V, Richardson A, Pearson J, Vallone D. Correlates of current menthol cigarette and flavored other tobacco product use among U.S. young adults. Addict Behav. 2016:62:35-41.

34. Larson R, Richards M. Daily companionship in late childhood and early adolescence: changing developmental contexts. Child Dev. 1991;62(2):84-300.

35. Bandura A. Social learning theory. Prentice Hall: Englewood Cliffs (NJ); 1977.

36. Robinson LA, Dalton 3rd WT, Nicholson LM. Changes in adolescents' sources of cigarettes. J Adolesc Health. 2006;39(6):861-7.

37. White MM, Gilpin EA, Emery SL, Pierce JP. Facilitating adolescent smoking: who provides the cigarettes? Am J Health Promot. 2005;19(5):355-60.

38. Eder D. The cycle of popularity: interpersonal relations among female adolescence. Sociol Educ. 1985;58(3):154-65.

39. Darling H, Reeder Al, McGee R, Williams S. Brief report: disposable income, and spending on fast food, alcohol, cigarettes, and gambling by New Zealand secondary school students. J Adolesc. 2006;29(5):837-43.

40. Wong G, Glover M, Nosa V, Freeman B, Paynter J, Scragg R. Young people, money, and access to tobacco. N Z Med J. 2007;120(1267):U2864.

\section{Submit your next manuscript to BioMed Central and we will help you at every step:}

- We accept pre-submission inquiries

- Our selector tool helps you to find the most relevant journal

- We provide round the clock customer support

- Convenient online submission

- Thorough peer review

- Inclusion in PubMed and all major indexing services

- Maximum visibility for your research

Submit your manuscript at www.biomedcentral.com/submit
Biomed Central 